\title{
Awareness of family medicine discipline among clinical medical students of Bayero University, Kano, Nigeria
}

\author{
Tanko Salihu Tanimua ${ }^{a}$ Godpower Chinedu Michaela (D) Aliyu Ibrahim ${ }^{b}$ (D) Bukar Alhaji Grema** (D) and \\ Abubakar Abiso Mohammeda (iD)
}

${ }^{a}$ Department of Family Medicine, Aminu Kano Teaching Hospital, Kano, Nigeria

${ }^{b}$ Department of Paediatrics, Aminu Kano Teaching Hospital, Kano, Nigeria

*Corresponding author, email: bugrema@yahoo.com

Introduction: Undergraduate medical education requires the studying of a wide range of medical specialties to produce the future workforce of the healthcare system. Family medicine (FM), a relatively new specialty in Nigeria, aims at supplying doctors capable of providing comprehensive healthcare for the majority of the population. However, many Nigerian medical schools (Bayero University inclusive) are yet to include FM in their undergraduate curriculum.

Methods: This was a descriptive cross-sectional study of 178 respondents randomly and proportionately selected from 400-, 500and 600-level medical students of Bayero University Kano. Using a structured questionnaire, their awareness of FM discipline, specialty preferences, factors influencing specialty preferences and their views on the relevance of FM in improving health systems were assessed.

Results: A majority of the respondents (60.7\%) were males and most (93.8\%) had heard of FM. However, only $19.7 \%$ of respondents were aware that FM was taught in the undergraduate programme of medical schools; $86 \%$ were aware of a postgraduate FM programme. FM (22.5\%) was the second most preferred specialty following surgery (23.6\%). Personal interest in the specialty was the main $(76.5 \%)$ reason for preference. Only $2.9 \%$ believed the postgraduate training for FM had a longer duration. All respondents believed FM was relevant as a specialty.

Conclusion: The knowledge and perception of the FM discipline among clinical medical students of Bayero University was good. They expressed that FM was relevant in the healthcare system as shown in their preference for the specialty, which ranked second among other specialties.

Keywords: awareness, family medicine, medical students, specialty preference

\section{Introduction}

The 2008 World Health Report reminded the world that primary health care was needed 'Now More Than Ever' in order to achieve equitable access to health for all. To achieve this universal coverage, leadership and public policy reforms are needed, and recognition that the heart of health service delivery that 'puts people first' is primary care. ${ }^{1}$ Family physicians are the heart of primary care in many health systems. ${ }^{2}$

Family Medicine is the discipline variously known as General Practice, Family Practice or Primary Care. It is a discipline that integrates several medical specialties into a new whole. It is concerned with the holistic approach to patient care in which the individual is seen in totality, and in the context of the family and community. ${ }^{3}$

A family physician functions in primary, secondary or tertiarycare centres as a specialist clinician and provides first contact and continuity of care to all the individuals in the defined population, without any limitations of age, sex, organ, or disease. $\mathrm{He} / \mathrm{she}$ is an expert in managing undifferentiated illnesses, manages multiple problems in the same patient, either acute or chronic, be it at the preventive, promotive, curative, rehabilitative or palliative care level. ${ }^{4}$ The family physician is an expert in providing whole-person care by taking care of the physical, mental, social and spiritual health with consideration of the patient's fears and concerns about his/her health issues. The family physician continues and coordinates the care when referral to multiple specialists is needed.
The World Health Organization (WHO) declared that primary health care was the key to 'health for all by the year 2000 ' at the Alma-Ata Conference on Primary Health Care in 1978, but unfortunately the role of family medicine was not clarified. ${ }^{5}$ In a joint WHO-Wonca (World Organization of Family Doctors) conference in 1994, WHO formally endorsed the contribution of family medicine to medical practice and education. In 2009, the 62nd World Health Assembly urged its member states to train and retain adequate numbers of health workers, including family physicians, and to encourage the implementation of vertical programmes in the context of integrated primary health care. ${ }^{6}$

Undergraduate medical training is the primordium from which progressive postgraduate medical specialties thrive all over the world. Medical education requires undergraduate students to study a wide range of medical specialties. The preference of medical specialties chosen by medical graduates plays an important part in the future workforce in the healthcare system, especially in times of over- or undersupply of doctors. ${ }^{7}$ Postgraduate training in family medicine strives to supply doctors capable of providing comprehensive care for the majority of the medical needs in a population.

Family medicine, a relatively new specialty in Nigeria, is now well recognised as an academic discipline and occupies an increasingly important role in the medical curricula of universities. ${ }^{8}$ Medical education in Nigeria is regulated by the Medical and Dental Council of Nigeria (MDCN) but the National Universities 
Commission (NUC) is the body that regulates all training in all tertiary institutions in the country. Hence, the NUC has directed universities offering undergraduate medical training to create departments of family medicine and that undergraduate medical students should spend some periods of posting in the departments of family medicine. The inclusion was informed by the need to train physicians who will adapt their knowledge, competence and skills to the unique and challenging environment of a developing country like Nigeria. However, medical schools in the country are yet to include family medicine in their undergraduate curriculum, Bayero University included. A recognised factor by a number of authors is that early exposure of medical students to a family medicine curriculum at the undergraduate level has significant influence on their choice of the discipline for residency. ${ }^{9}$ Personal social values were also found to be characteristically strong in influencing a graduate's career choice of family medicine. For example, some preferred a specialty with broad clinical competence while others considered guaranteed employment on completion of residency as attractive enough. ${ }^{10}$

In the light of these findings, we studied the awareness of the family medicine discipline among clinical medical students of Bayero University, Kano, with regard to their knowledge and the relevance of the specialty as well as to increase their future career options.

\section{Materials and method}

\section{Study area}

The study was carried out in the clinical section (sited within Aminu Kano Teaching Hospital) of Bayero University medical school, Kano, in July 2016. The medical school of Bayero University is the 14th medical school/college established in Nigeria. The Faculty of Clinical Sciences came into existence on the April 1, 2014 as an offshoot of the Faculty of Medicine, which was established in 1986.The undergraduate medical programme at Bayero University, Kano, has adopted a community-oriented and community-based educational philosophy for the training of its doctors. The programme of training has been designed in such a way that doctors produced from Bayero University, Kano, will be well equipped and motivated to practise in the urban and rural areas of Nigeria.

\section{Study population}

The study population was 400- (4th year), 500- (5th year) and $600-$ level (6th year) medical students of Bayero University, Kano with a class population of 129 students in the 400 level, 93 students in the 500 level and 82 students in the 600 level (a total population of 304 students)

\section{Sample size estimation}

Sample size will be calculated using the formula:11

$n=N$

$1+N(\mathrm{e})^{2}$

Where

$n=$ desired minimum sample size (when population is less than $10000)$

$N=$ population size (304 students)

$\mathrm{e}=$ level of precision usually set at $5 \%=0.05$.

Therefore

$n=304$

$1+304(0.05)^{2}$ $n=304$

1.76

$n=172.73 \approx 173$

Thus, 173 participants were therefore recruited proportionately from the 400 -level $(129 / 304 \times 173=73)$, 500 -level $(93 / 304 \times 173=53)$ and 600 -level $(82 / 304 \times 173=47)$ students.

\section{Inclusion and exclusion criteria}

Participants were included if they were present in the classroom at the time of administering the questionnaire and gave their consent.

Participants were excluded if they declined consent.

\section{Study design}

The study was a descriptive cross-sectional design.

\section{Sampling method}

Systematic random sampling was used. The first participant in each level was selected by simple random sampling using the balloting technique. If any of the participants declined consent, the next consenting eligible student was administered the questionnaire. The number of participants was drawn proportionately from each class level until the minimum sample size was reached.

\section{Study procedure and data collection}

Information was given to the students by the investigators in English on the objectives of the study as well as their right to refuse participation. A pretested structured questionnaire was administered by the investigators to each consenting eligible participant. The questionnaire assessed the participant's sociodemographic characteristics, level of awareness of the family medicine discipline, their specialty preferences, factors influencing their specialty preference and their views on the relevance of family medicine discipline to improving health systems.

\section{Data analysis}

All data collected were cleaned and checked for completeness before being entered onto a computer and analysed using the Statistical Package for Social Science (SPSS ${ }^{\circledR}$ ) version 20.0 software (SPSS Inc., Chicago, IL, USA). The data were presented in tables and summarised as frequencies and percentages.

\section{Ethical approval}

Ethical approval for the study was sought and obtained from the medical research ethics committee of Aminu Kano Teaching Hospital (AKTH), Kano (NHREC/21/08/2008/AKTH/EC/1697).

\section{Results}

There were $108(60.7 \%)$ males and 70 (39.3\%) females with a male to female ratio of 1.5:1. Seventy-three (41\%), 57 (32\%) and $48(27 \%)$ were in the fourth, fifth and sixth year of training respectively. The majority $(167,93.8 \%)$ of the respondents had heard of family medicine, and most information about the specialty was obtained from the department of family medicine, while only 5 (3\%) gained information from reading textbooks (Table 1).

Only 35 (19.7\%) respondents were aware that family medicine was being taught in the undergraduate programme of medical 
Table 1: Information on family medicine

\begin{tabular}{lcc|}
\hline Information & Frequency & Percent (\%) \\
\hline Heard of family medicine? & 167 & \\
Yes & 11 & 93.8 \\
\hline No & & 6.2 \\
\hline Source of information on FM & 17 & \\
\hline Media & 22 & 10.2 \\
\hline Relatives & 8 & 13.2 \\
\hline Internet & 6 & 4.8 \\
\hline Journal & 52 & 3.6 \\
\hline Lecturers & 5 & 31.1 \\
\hline Books & 57 & 3.0 \\
\hline Dept of FM & & 34.1 \\
\hline
\end{tabular}

Note: $F M=$ family medicine.

schools while $143(80.3 \%)$ were unaware; but $153(86 \%)$ were aware of a postgraduate family medicine programme while only $25(14 \%)$ were not aware. Despite this, only $42(23.6 \%)$ were interested in the postgraduate family medicine programme while $136(76.4 \%)$ respondents were not interested in family medicine (Table 2). However, there was no specified reason other than not being interested in the specialty by 50 (36.8\%) respondents and only $4(2.9 \%)$ believed the postgraduate training for family medicine was of a longer duration. However, among all specialties surgery was the most preferred specialty $(22.5 \%)$, followed by family medicine $(21.9 \%)$ and the least was ear, nose and throat surgery $(1.1 \%)$. Furthermore, the respondents' personal interest in the specialties was the main reason for preference $(76.5 \%)$ while duration of specialty postgraduate training accounted for only $2.8 \%$ of the cases.

All the respondents believed family medicine was relevant as a specialty in the healthcare system. In all, 119 (66.9\%) respondents were of the view that family physicians can practise in both private and public hospital settings (Table 3). However, 33 $(18.5 \%)$ did not know the exact practice location of family physicians while only $9(5.1 \%)$ believed they could only practise in a private setting; furthermore, the majority of the respondents (46.1\%) believed that the focus of care by the family physician is individuals and their families while only $3(1.7 \%)$ respondents reported families only.

Table 4 shows that the majority of the respondents in all the classes had heard of FM, though this observation was predominantly among the 500-level medical students (98\%); it was not statistically significant (Fisher's exact test $=4.575$, $p=0.104$ ). However, most of the 500 -level students (70\%) did not like FM as a career but this observation was also not statistically significant (chi-square $=4.997, \mathrm{df}=2, p=0.85$ ). Generally, there was poor awareness of the FM undergraduate programme. However, more 400 -level students (26\%) were aware of the FM undergraduate programme than those in the other groups but this observation was not statistically significant (chi-square $=$ 3.593 , $\mathrm{df}=2, p=0.177$ ). A majority of the students in all the classes were aware of the postgraduate FM programme, though
Table 2: Preference for family medicine specialty among medical students

\begin{tabular}{|c|c|c|}
\hline Family medicine preference & Frequency & Percent (\%) \\
\hline \multicolumn{3}{|c|}{ Do you have interest in FM as a career? } \\
\hline Yes & 42 & 23.6 \\
\hline No & 136 & 76.4 \\
\hline \multicolumn{3}{|l|}{ Reason for not choosing FM specialty } \\
\hline Just not interested & 50 & 36.8 \\
\hline Challenges due to duration & 4 & 2.9 \\
\hline Difficult field & 47 & 34.6 \\
\hline Lack of information on FM & 17 & 12.5 \\
\hline Multiple reasons & 18 & 13.2 \\
\hline \multicolumn{3}{|l|}{ Specialty preference for $P G$ training } \\
\hline None & 6 & 3.4 \\
\hline Medicine & 31 & 17.4 \\
\hline Surgery & 40 & 22.5 \\
\hline Paediatrics & 16 & 9.0 \\
\hline Family medicine & 39 & 21.9 \\
\hline Obstetrics and gynaecology & 22 & 12.4 \\
\hline Ear, nose \& throat & 2 & 1.1 \\
\hline Radiology & 3 & 1.7 \\
\hline Ophthalmology & 8 & 4.5 \\
\hline Psychiatry & 4 & 2.2 \\
\hline Community medicine & 7 & 3.9 \\
\hline \multicolumn{3}{|c|}{ Factors influencing specialty preference } \\
\hline Personal interest & 136 & 76.5 \\
\hline The demand for the specialty & 25 & 14.0 \\
\hline The duration of training & 5 & 2.8 \\
\hline Popularity of the specialty & 12 & 6.7 \\
\hline Total & 178 & 100 \\
\hline
\end{tabular}

Table 3: Views of medical students concerning relevance of family medicine in health care

\begin{tabular}{lcc}
\hline Medical students' views & Frequency & Percent (\%) \\
\hline Knowledge of practice location of FP & & \\
\hline Private clinics only & 9 & 5.1 \\
\hline Public hospitals only & 17 & 9.5 \\
\hline Both public/private hospitals & 119 & 66.9 \\
\hline Idon't know & 33 & 18.5 \\
\hline Focus of care by family physicians & & \\
\hline Families only & 3 & 1.7 \\
\hline Individuals and their families & 82 & 46.1 \\
\hline Families and communities & 59 & 33.1 \\
\hline I don't know & 34 & 19.1 \\
\hline Total & 178 & 100 \\
\hline
\end{tabular}

Note: FP = family physicians.

the awareness was greatest in the 600-level group but this observation was also not statistically significant (chi-square = 5.120, $\mathrm{df}=2 ; p=0.85$ ). 
Table 4: Awareness of family medicine programmes according to the various classes

\begin{tabular}{|c|c|c|c|}
\hline Class & Yes $(n / \%)$ & No $(n / \%)$ & Total (n/\%) \\
\hline \multicolumn{4}{|c|}{ Have heard of FM? ${ }^{a}$} \\
\hline Level 400 & $65(89 \%)$ & $8(11 \%)$ & $73(100 \%)$ \\
\hline Level 500 & $56(98 \%)$ & $1(2 \%)$ & $57(100 \%)$ \\
\hline Level 600 & $46(96 \%)$ & $2(4 \%)$ & $48(100 \%)$ \\
\hline Total & 167 & 11 & 178 \\
\hline \multicolumn{4}{|c|}{ Interest in FM as a career? ${ }^{b}$} \\
\hline Level 400 & $11(15 \%)$ & $62(85 \%)$ & $73(100 \%)$ \\
\hline Level 500 & $17(30 \%)$ & 40 (70\%) & $57(100 \%)$ \\
\hline Level 600 & $14(29 \%)$ & $34(71 \%)$ & $48(100 \%)$ \\
\hline Total & 42 & 136 & 178 \\
\hline \multicolumn{4}{|c|}{$\begin{array}{l}\text { Aware of undergraduate FM } \\
\text { programme? }\end{array}$} \\
\hline Level 400 & $19(26 \%)$ & $54(74 \%)$ & $73(100 \%)$ \\
\hline Level 500 & $10(18 \%)$ & 47 (82\%) & $57(100 \%)$ \\
\hline Level 600 & $6(13 \%)$ & 42 (87\%) & $48(100 \%)$ \\
\hline Total & 35 & 143 & 178 \\
\hline \multicolumn{4}{|c|}{$\begin{array}{l}\text { Aware of postgraduate FM } \\
\text { programme? }\end{array}$} \\
\hline Level 400 & $58(80 \%)$ & $15(20 \%)$ & $73(100 \%)$ \\
\hline Level 500 & $50(88 \%)$ & $7(12 \%)$ & $57(100 \%)$ \\
\hline Level 600 & 45 (94\%) & $3(6 \%)$ & $48(100 \%)$ \\
\hline Total & 153 & 25 & 178 \\
\hline
\end{tabular}

aFisher's exact test $=4.575, p=0.104$.

${ }^{\mathrm{b}}$ Chi-square $=4.997, \mathrm{df}=2, p=0.85$

${ }^{c}$ Chi-square $=3.593, \mathrm{df}=2, p=0.177$.

dFisher's exact test $=5.120, p=0.85$.

\section{Discussion}

Medical education requires the exposure of undergraduates to a wide range of medical specialties, the choice of which has significant implications in planning a balanced workforce for better healthcare delivery. ${ }^{12}$

A high level of awareness of the family medicine discipline was recorded in this study (93.8\%) among clinical medical students of Bayero University, Kano. This is similar to the level of awareness in Ghana (88.0\%) and Greece (95\%) but higher than the $47 \%$ recorded among medical students in Dar es Salaam, Tanzania, which was attributed to their profound lack of understanding of the role of family physicians..$^{10,13,14}$ Most of the information about the specialty (34.4\%) was obtained from the department of family medicine and their lecturers (31.1\%) while only $3.0 \%$ got the information from reading books. These sources of information were dissimilar to the experiences of the medical students in Ghana, where their main sources of information were from fellow students (76.8\%), medical journals (4.8\%) and the Internet (4.8\%). ${ }^{13}$ This dissimilarity could be because Bayero University Kano is yet to commence a family medicine undergraduate programme where medical students will have clinical rotations. However, participants assess medical care at the staff clinic of AKTH and sometimes accompany their relatives to assess care in the General Outpatient Clinic, which are all run by family physicians. These encounters are therefore important opportunities to inform and educate medical students about the specialty. However, $6.2 \%$ of the study respondents were unaware of the family medicine discipline and this proportion of students would have lost the opportunity of selecting family medicine (should they be interested in it) and adding to the critical mass of family physicians that the postgraduate colleges are seeking to build to improve primary care services in Nigeria.

All the respondents believed that family medicine as a specialty was relevant in the healthcare system. This is an indication that the students had good knowledge and perception of its relevance in healthcare delivery. Two-thirds (66.9\%) of the respondents also had correct knowledge of where family physicians could practise, such as public and private health facilities. The remaining third (33.1\%) that were either ignorant or had incorrect knowledge of the practice location of family physicians could be dissuaded from pursuing a FM postgraduate programme, as this choice may limit their job search after completion of the programme. Similarly, only $46.1 \%$ clearly understood that family physicians focus on individuals and their families while a minority (1.7\%) still believed that family physicians focus on families only. Incorrect perceptions about the family medicine core values such as those demonstrated may also limit the uptake of family medicine as a career path among respondents. Furthermore, the majority of the students (80.3\%) were not aware of family medicine being taught at undergraduate level while $86 \%$ were aware of postgraduate training in family medicine. This is not surprising because of the absence of a family medicine undergraduate curriculum in some medical schools in the country, Bayero University included. The students come into contact with family medicine residents only while they are on postings in other departments.

If medical students are not exposed to family medicine during their education, they may be unaware of the content and challenges associated with family practice and are less likely to choose family medicine as a career. In this study, it was observed that the students' willingness to choose family medicine as a career was not in agreement with the high knowledge and positive perceptions previously highlighted. Only $23.3 \%$ of the students were interested in postgraduate training in family medicine. However, when given other specialty choices for postgraduate training, family medicine ranked second $(21.9 \%)$ after surgery $(22.5 \%)$. This was closely followed by internal medicine (17.4\%) and obstetrics and gynaecology (12.4\%). The least preferred specialty in this study was ear, nose and throat surgery (1.1\%). This suggests that family medicine could readily be the most preferred specialty in the future when many medical institutions may have commenced the undergraduate programme, which is a relatively new specialty. This study result contrasted with studies from Ghana (2.4\%) and Greece (4.3\%), where family medicine was the least preferred medical specialty for postgraduate training. ${ }^{10,13}$ The core clinical specialties of surgery, internal medicine, paediatrics, and obstetrics and gynaecology are frequently chosen at the expense of other specialties such as family medicine. ${ }^{15-17}$ However, a study by Gadanya and Ismail revealed that despite obstetrics and gynaecology and paediatrics being the most preferred specialty at graduation, none of the students were pursuing a career in obstetrics and gynaecology at 10 years post-graduation. There was, rather, an attraction towards family medicine, internal medicine, radiology and community medicine. ${ }^{16}$ Thus, there could be differences in the perception of undergraduate medical students about these specialties compared with their different experiences of these departments as graduates.

The reason stated by most of our study respondents for not choosing family medicine as a specialty was that they were just not interested (36.8\%). Other reasons were the perception that 
family medicine was a difficult field (34.6\%), multiple reasons $(13.2 \%)$, and challenges due to duration of the posting (2.9\%). This finding also contrasted with studies from other countries where the reasons mostly stated for not choosing family medicine were inadequate knowledge of the specialty, lack of prestige compared with other specialties, perceived low intellectual content, difficulty in mastering the content of the specialty and negative comments about family physicians by other specialists. ${ }^{10,18,19}$

The choice of a specialty for postgraduate training was influenced by personal interest in $76.5 \%$ of the respondents. Other factors stated were the demand for the specialty (14.0\%), popularity of the specialty $(6.7 \%)$ and the duration of the training (2.8\%). The findings from this study are similar to those reported from studies in Ghana and Kano. ${ }^{10,15}$ Likewise, Tolhurst et al. found personal social values to be a characteristically strong influencer on a graduate's career choice. Some of the respondents in the study preferred a specialty with broad clinical competence while others considered guaranteed employment on completion of residency as attractive enough. ${ }^{9}$ Insights into the reasons underlying the choice of medical specialties in a country can be utilised to improve medical career planning and guide them towards careers that serve their aspirations as well as the health needs of the society.

Finally, the popularity of family medicine seems to be growing among the medical students; this was shown by the greater awareness among the younger classes (4th and 5th year) when compared with the older class (6th year), though this observation was not statistically significant. This observation may be related to the recent introduction of a family medicine curriculum in Nigerian medical undergraduate programmes; therefore the fresher students are often beneficiaries of such early knowledge, hence a better awareness of family medicine among them would not be surprising. ${ }^{20}$

\section{Conclusion}

The knowledge and perception of the family medicine discipline among clinical medical students of Bayero Medical School was quite good. There was also an expression of the relevance of family medicine in the healthcare system. However, not many were willing to specialise in the specialty due to lack of interest and the perceived difficulty of the specialty, though family medicine was the second most preferred specialty when ranked among other specialties. Therefore, teachers of family medicine should take advantage of the current high level of awareness among medical students to improve their understanding of the specialty through career counselling and draw their interest. Students need to see a future in family medicine as a personally satisfying and beneficial career choice. Awareness creation concerning the fundamental characteristics and attributes of family medicine should begin in the preclinical section of medical schools in order to bridge the gap between awareness of the specialty and its preference for postgraduate training. Medical schools in Nigeria should also expedite inculcation of a family medicine curriculum into their undergraduate programme to ensure early exposure of medical students to the discipline.

The impact of career counselling on specialty preference among medical students, house officers and their eventual areas of specialisation should be domains for future research.

\section{Limitations of the study}

The cross-sectional nature of the study design could not allow for trajectories of eventual areas of specialisation, therefore longitudinal studies are required.

Conflict of interest - The authors declare no conflict of interest in the study.

Acknowledgement - The authors would like to acknowledge the clinical students of Bayero Medical School for consenting to participate in the study. They also wish to thank Mallam Saminu Shehu of the Department of Family Medicine, Aminu Kano Teaching Hospital, Kano for running errands while preparing this manuscript.

\section{ORCID}

Godpower Chinedu Michael (iD) http://orcid.org/0000-00034008-4483

Aliyu Ibrahim (iD http://orcid.org/0000-0003-0018-1828

Bukar Alhaji Grema iD http://orcid.org/0000-0002-2316-6455

Abubakar Abiso Mohammed (iD) http://orcid.org/0000-00020412-0363

\section{References}

1. World Health Organization. World Health Report 2008 - primary health care (now more than ever). 2008 [cited 2016 July 13]. Available from: www.who.int/whr/2008/en/.

2. Kidd M. Family doctors in health systems. In: Kidd M, editor. The contribution of family medicine to improving health systems. 2nd ed.. London: Radcliffe Publishing; 2013. p. 41-73.

3. Yohanna S, Pitman S. Faculty of Family medicine residents' handbook: curriculum and syllabus for the residency training programme towards the fellowship in family medicine. Lagos: National postgraduate medical college of Nigeria; 2014. p. 1-5.

4. Phillips WR, Haynes DG. The domain of family practice: Scope, role, and function. Fam Med. 2001;33:273-7.

5. World Health Organization. The Alma-Ata Conference on primary health care. WHO Chronicle. 1978;32:409-30.

6. World Health Assembly 62.12. Geneva, Switzerland: World Health Organization; 2009 [cited 2016 April 20]. Available from: http://www. who.int/hrh/resources/A62_12_EN.pdf.

7. Khader Y, Al-Zoubi D, Amarin Z, Alkafagei A, Khasawneh M, Burgan $S$, et al. Factors affecting medical students in formulating their specialty preferences in Jordan. BMC Med Educ. 2008;8:32. https:// doi.org/10.1186/1472-6920-8-32

8. Frey JJ. A murky future for academic primary care. Br J Gen Pract. 2003;53:179-80.

9. Tolhurst $\mathrm{H}$, Stewart M. Becoming a GP - a qualitative study of the career interests of medical students. Aust Fam Physician. 2005;34: 204-6.

10. Essuman A, Anthony-Krueger C, Ndanu TA. Perceptions of medical students about family medicine in Ghana. Ghana Med J. 2013;47(4): 178-84.

11. Kasiulevicius K, Sapoka V, Filipaviciute R. Sample size calculation in epidemiological studies. Gerontologija. 2006;7:225-31.

12. Mash R, Downing R, Moosa S, De Maeseneer J. Exploring the key principles of family medicine in sub-Saharan Africa: International Delphi consensus process. SA Fam Pract. 2008;50(3):60-5.

13. Anargiros $M$, Constantinos $M$, Alevigos A. General practice as a career choice among undergraduate medical students in Greece. BMC Med Educ. 2007;7:15.

14. Aghan EL. Perception of final year undergraduate medical students towards family medicine in Dar es Salaam, Tanzania [Unpublished master's dissertation]. Dar es Salaam: Aga Khan University, East Africa; 2013. 
15. Asani MO, Gwarzo GD, Gambo MJ. Preference of specialty choices among final year medical students of Bayero University Kano. Sahel Med J. 2016;19:155-8.

16. Gadanya MA, Ismail A. Specialty choices of final year medical students: A 10-year follow-up. 2014;11:110-13.

17. Egenti BN, Abana OR, Chineke HN, Egwatu CC, Adogu POU, Ilika AL. Perception of community medicine as a specialty of choice among clinical medical students in a Nigerian University: Any remedies. British Journal of Education Society and Behavioral Science. 2016;16: 1-8.

18. Joyce CM, McNeil JJ. Fewer medical graduates are choosing general practice: a comparison of four cohorts, 1980-1995. Med J Aust; 185:102-4.
19. Mackean P, Gutkin C. Fewer medical students selecting family medicine: can family practice survive. Can Fam Physician. 2003;49: 408-9.

20. Nigerian University Commission approves seven-year, four-year MBBS/BDS Program in new minimum academic standards. 2014 [cited 2017 March 6]. Available from: https://www.medicalworldnigeria. com/2015/11/nuc-approves-seven-year-four-year-mbbs-bdsprogram-in-new-minimum-academic-standards\#.WLOu8m8rLIU.

Received: 20-01-2017 Accepted: 25-03-2017 